\title{
Experimental Testing of the Water Distillation System with Regard to Heat and Cooling Generation by Means of Reversible Thermochemical Reactions
}

\author{
Sergii Bespalko ${ }^{1, *}$, Oleksii Halychyi ${ }^{1}$, Sviatoslav Poliakov $^{1}$, Valentyn $_{\text {Tkachenko }}^{2}$, and Taisiia Naumenko ${ }^{1}$ \\ ${ }^{1}$ Cherkasy State Technological University, Department of Energy Technologies, Shevchenko Boulevard, 460, 18006 Cherkasy, Ukraine \\ ${ }^{2}$ Cherkasy State Technological University, Department of Electrotechnical Systems, Shevchenko Boulevard, 460, 18006 Cherkasy, \\ Ukraine
}

\begin{abstract}
The paper presents the results of an experimental study on the exothermal heat and endothermal cooling generation under vacuum conditions using a water distillation system of special design. The heat and cooling are generated when $\mathrm{KOH}$ and $\mathrm{NH}_{4} \mathrm{NO}_{3}$ crystals are dissolved as a result of natural mixing in the water, distilled from $\mathrm{NH}_{4} \mathrm{NO}_{3}$ and $\mathrm{KOH}$ liquid solutions, respectively. The time evolutions of the temperatures measured in $\mathrm{KOH} \rightarrow \mathrm{H}_{2} \mathrm{O} \rightarrow \mathrm{NH}_{4} \mathrm{NO}_{3}$ and $\mathrm{NH}_{4} \mathrm{NO}_{3} \rightarrow \mathrm{H}_{2} \mathrm{O} \rightarrow \mathrm{KOH}$ experiments are presented and discussed. It has been shown that under vacuum conditions, the endothermal effect of $\mathrm{NH}_{4} \mathrm{NO}_{3}$ dissolution in water is stronger than that observed at atmospheric pressure, while the exothermal effect of $\mathrm{KOH}$ dissolution in water is weaker. The experimental results obtained will be used to develop the dual thermochemical heat storage and cooling generating system in order to utilize solar heat in the summer.
\end{abstract}

\section{Introduction}

Recently, many R\&D efforts have focused on developing different thermochemical systems and the ability to store heat and generate cooling. This is due to the fact that this technology has a wide range of applications in the HVAC systems, industrial waste heat recovery and solar heat utilization and is very attractive from the environmental and economic perspectives. Comprehensive reviews on the recent advances in this field of study are presented in [1-4]. However, despite the maturity of some of the thermochemical systems, the development of the new system designs is of great interest.

For this reason, in this particular experimental study, we have focused our attention on studying the ability of a water distillation system of special design, to generate exothermal heat and endothermal cooling, using two substances with different chemical properties simultaneously, namely, potassium hydroxide $\mathrm{KOH}$ and ammonium nitrate $\mathrm{NH}_{4} \mathrm{NO}_{3}$.

\section{Materials and methods}

\subsection{Description of the experimental setup and measurement equipment}

A scheme of the experimental facility used for water evaporation from $\mathrm{KOH}$ and $\mathrm{NH}_{4} \mathrm{NO}_{3}$ solutions, is presented in Fig. 1. It consists of the heater, used as a main heat source for water evaporation from the liquid solution, a stainless steel heat exchanger serving as a condenser and chemical tubes acting as thermochemical reactors, fittings, valves and measurement equipment.

The upper and lower chemical tubes contained $\mathrm{KOH} / \mathrm{NH}_{4} \mathrm{NO}_{3}$ solutions and pure $\mathrm{NH}_{4} \mathrm{NO}_{3} / \mathrm{KOH}$ respectively and were sealed by rubber plugs with central holes for installation of the temperature sensors. In the experiments, temperatures were measured and automatically recorded by a measuring system consisting of (1) three platinum temperature resistors HEL-705 (Honeywell), calibrated with an accuracy of $\pm 0.5 \mathrm{~K}$ and installed in hollow pipes made of 316 stainless steel, (2) three signal amplifiers WAD-A-MAX (Acon), (3) a data logger WAD-AD-12-128HL (Acon) and (4) a personal computer. To ensure good thermal contact between the internal surfaces of the metal pipes and the temperature sensors, the former were filled with glycerin.

In our study, two types of experiments were conducted. The first was to study the cooling generation when pure $\mathrm{NH}_{4} \mathrm{NO}_{3}$ is dissolved in the condensate, generated by the distillation unit. Here, to ensure water evaporation from the $\mathrm{KOH}$ solution, a sand bath with a $1.5 \mathrm{~kW}$ electric hot plate AU 486 (Aurora) was used as a heater. Hereafter, the first experiment will be referred to as $\underbrace{\mathrm{KOH}}_{\text {solution }} \rightarrow \underbrace{\mathrm{H}_{2} \mathrm{O}}_{\text {liquid }} \rightarrow \underbrace{\mathrm{NH}_{4} \mathrm{NO}_{3}}_{\text {pure }}$. The second experiment was intended to assess the heat generation, while pure $\mathrm{KOH}$ is dissolved in the condensate produced by the distillation unit. Here, to ensure water evaporation from the $\mathrm{NH}_{4} \mathrm{NO}_{3}$ liquid solution, an ultra-thermostat UT-15 (not shown in the scheme) filled with water was applied.

\footnotetext{
* Corresponding author: s.bespalko@,chdtu.edu.ua
} 
Hereafter, the second experiment will be referred to as $\underbrace{\mathrm{NH}_{4} \mathrm{NO}_{3}}_{\text {solution }} \rightarrow \underbrace{\mathrm{H}_{2} \mathrm{O}}_{\text {liquid }} \rightarrow \underbrace{\mathrm{KOH}}_{\text {pure }}$. In both experiments, UO-1 (not shown in the scheme) was used to circulate cold water through the heat exchanger to condense the water vapor eventually. A special design separator was installed behind the upper chemical tube to ensure the entire separation of the water vapor, generated from the tiny solution droplets containing the solute.
For the purpose of decreasing the evaporation temperature considerably, the water distillation was conducted under vacuum conditions. The vacuum was created using a water jet vacuum pump (Kartell) (not shown in the scheme) and the vacuum level was measured using a vacuometer Value with a division value equal to $2 \mathrm{kPa}$, as well as a barometer Baro 108THB, with a division value of $1 \mathrm{mmHg}$.

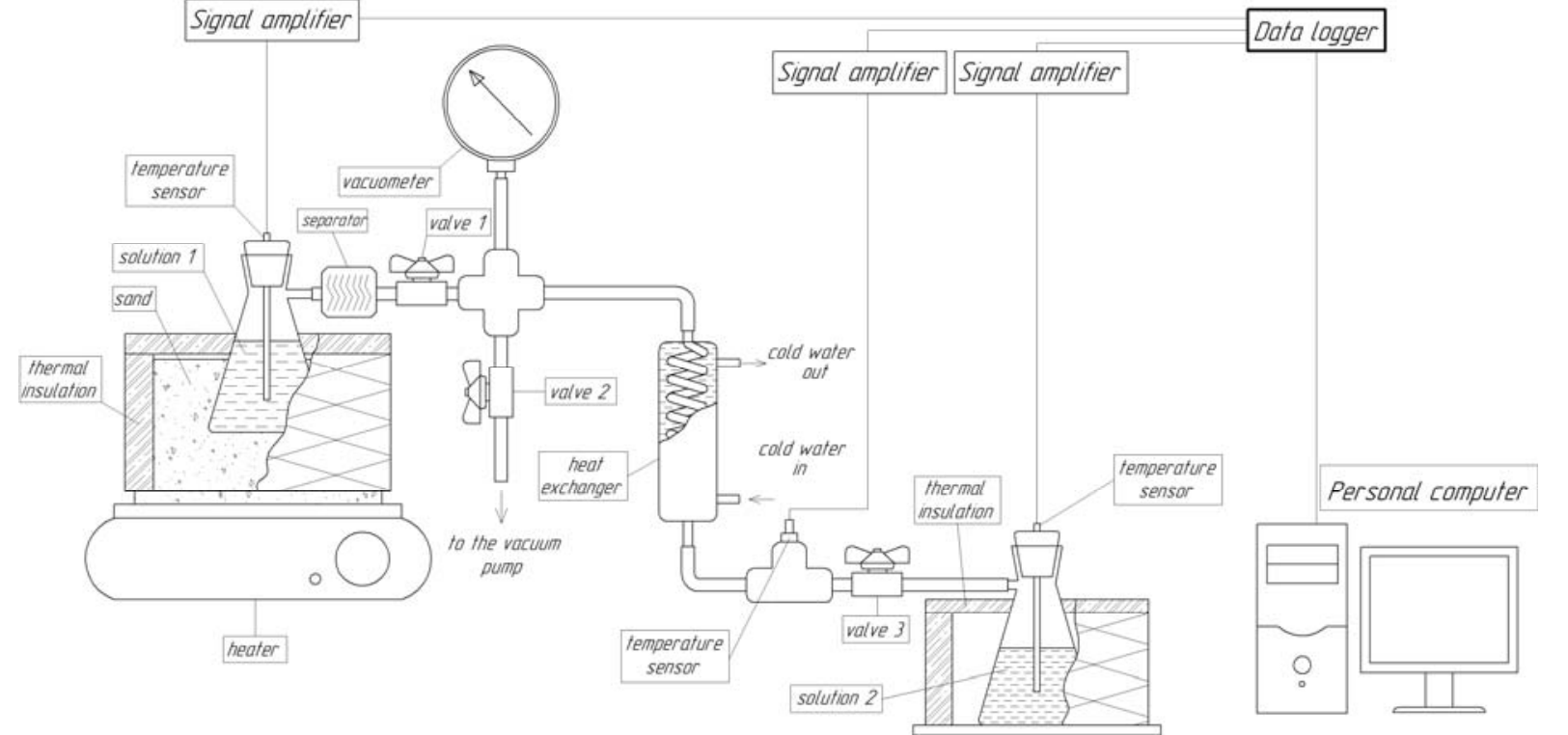

Fig. 1. Scheme of the experimental setup

For preparation of the liquid solutions, the distilled water was produced in our laboratory using a DE-4-2M (SZMO) distillation apparatus.

In each experiment, the initial temperature of the solutions and pure chemicals was $10{ }^{\circ} \mathrm{C}$. Pressure inside the distillation unit was almost uniform and equaled 4.5 $\mathrm{kPa}$ and $2 \mathrm{kPa}$ on the absolute scale in the first and second experiments, respectively. The mass of the vessels, distilled water and chemicals were measured using a FEN-300L (Dneproves) high-accuracy weighing machine.

\subsection{Experimental procedure}

The experimental procedure for studying the water distillation and the corresponding thermal effects of the dissolution reactions was as follows:

The upper chemical tube was first filled with the preprepared liquid solution, sealed with a rubber plug and then installed in the heater. In turn, the lower chemical tube was filled with the pure substance in order to be further dissolved in the water, generated by the distillation system. The initial concentrations of $\mathrm{KOH}$ and $\mathrm{NH}_{4} \mathrm{NO}_{3}$ solutions in the upper chemical vessel of both experiments were $70 \mathrm{wt} \%$ and $60 \mathrm{wt} \%$, respectively. The final solution concentrations in the lower chemical vessel, were selected in such a manner so as to achieve the highest endothermal and exothermal effects eventually, for the case of natural mixing as discussed in our previous work [5].

Chemical vessels, pipes and fittings were heat insulated with the mineral wool to minimize heat leakages in the experiments. After connecting tubes to the distillation system, a vacuum pump was triggered to create a vacuum within the system. When pressure reached the targeted level, valve 2 was closed. Next, the UO-1 apparatus was turned on to circulate cold water through the condenser. Then the data logger was triggered simultaneously with the heater.

The data acquisition system recorded the temperature of the solution heated in the upper vessel, the temperature of the condensate and the temperature of the substance in the lower chemical tube. The data acquisition frequency was set at $1 \mathrm{~Hz}$ and five separate experiments were conducted to define the average values of the temperatures measured. Finally, Mathcad 15 was used for data processing and presenting the collected data in graphical representations.

After finishing the temperature measurements, valves 1 and 3 were closed to prevent any water vapor absorption by the solutions. Final solution concentrations were defined as the difference between the initial and final weight of the vessels.

\subsection{Procedure for calculating the enthalpy changes of the solutions}

The solutions' enthalpy changes in $\mathrm{kJ} / \mathrm{kg}$ were calculated using the procedure presented in [5].

\section{Results and discussion}

\subsection{Endothermal cooling generation in vacuum}


The time evolution of the temperatures, measured in the water distillation from the $\mathrm{KOH}$ solution and endothermal cooling generation, is presented in Fig. 2.

The picture demonstrates that during first 4019 seconds, the solution temperature rises slightly from $10^{\circ} \mathrm{C}$ to $23.9^{\circ} \mathrm{C}$, which can be explained by a feature of the electrical heater used. Then the solution temperature rises sharply up to the boiling point of around $78.4{ }^{\circ} \mathrm{C}$ at 5261 seconds. After reaching the boiling point, water vapor is released from the heated solution.

In contrast to a single-component substance, e.g., water, where the saturation temperature remains uniform throughout the boiling process, the boiling of the twocomponent solution occurs at a non-constant temperature. For this reason, an increase in the temperature of the $\mathrm{KOH}$ solution during water evaporation is observed. The final temperature of the $\mathrm{KOH}$ solution achieved in our experiment was $156.2^{\circ} \mathrm{C}$.

Following evaporation, the water vapor was condensed in the condenser with a nearly constant temperature of around $10^{\circ} \mathrm{C}$ at the condenser outlet.
The temperature measured in the lower chemical vessels was nearly constant at around $10{ }^{\circ} \mathrm{C}$ until 7472 seconds, indicating no presence of the water flow coming from the condenser. After this time period, the temperature dropped to $-8.9{ }^{\circ} \mathrm{C}$, signifying the dissolution reaction of $\mathrm{NH}_{4} \mathrm{NO}_{3}$ crystals in the water. Curiously, but under vacuum conditions, the endothermal effect observed was stronger than that observed at atmospheric pressure with the other conditions being equal, as presented in our previous research [5], i.e. $-8.9^{\circ} \mathrm{C}$ under vacuum versus $-7.6^{\circ} \mathrm{C}$ at atmospheric pressure, for a $60 \%$ concentration of $\mathrm{NH}_{4} \mathrm{NO}_{3}$ solution.

The overall reaction can be written as:

$$
\underbrace{\mathrm{KOH}}_{\text {solution }}+\text { heat } \rightarrow \underbrace{\mathrm{H}_{2} \mathrm{O}}_{\text {liquid }}+\underbrace{\mathrm{NH}_{4} \mathrm{NO}_{3}}_{\text {pure }} \text { + endothermal cooling }
$$

In this reaction the overall endothermal cooling generated, was $-153 \mathrm{~kJ} / \mathrm{kg}$.

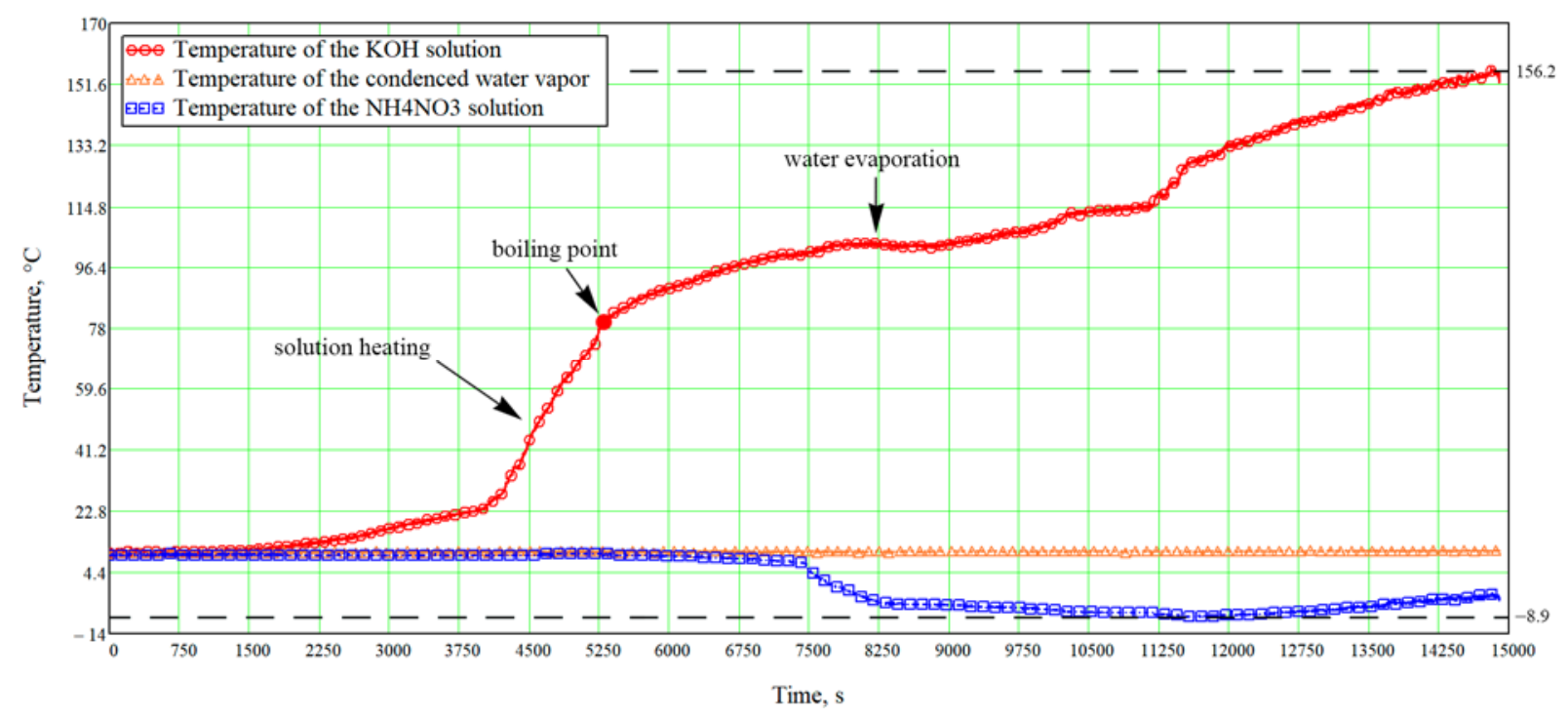

Fig. 2. Time evolution of the temperatures measured in the $\underbrace{\mathrm{KOH}}_{\text {solution }} \rightarrow \underbrace{\mathrm{H}_{2} \mathrm{O}}_{\text {liquid }} \rightarrow \underbrace{\mathrm{NH}_{4} \mathrm{NO}_{3}}_{\text {pure }}$ experiment

\subsection{Exothermal heat generation in vacuum}

The time evolution of the temperatures measured in the water distillation from the $\mathrm{NH}_{4} \mathrm{NO}_{3}$ solution and exothermal heat release is presented in Fig. 3.

From the picture it may be observed that the $\mathrm{NH}_{4} \mathrm{NO}_{3}$ solution is heated up to the boiling point during first 2950 seconds. The boiling begins at a temperature of around $28.7{ }^{\circ} \mathrm{C}$. Here, it should be pointed out that the $\mathrm{NH}_{4} \mathrm{NO}_{3}$ solution has a much lower boiling point than the $\mathrm{KOH}$ solution, i.e., $28.7^{\circ} \mathrm{C}$ for the $\mathrm{NH}_{4} \mathrm{NO}_{3}$ solution versus $78.4{ }^{\circ} \mathrm{C}$ for the $\mathrm{KOH}$ solution, neglecting the slight difference in pressures and concentrations in both experiments. After reaching the boiling point, water vapor is released from the $\mathrm{NH}_{4} \mathrm{NO}_{3}$ solution. The maximal temperature before which the $\mathrm{NH}_{4} \mathrm{NO}_{3}$ solution was heated was $48.6{ }^{\circ} \mathrm{C}$, attaining entire water evaporation from the solution.
Similar to the previous experiment, the condenser provided a constant temperature of the condensed water vapor of around $10{ }^{\circ} \mathrm{C}$ at the outlet.

After 4379 seconds, the temperature measured in the lower chemical vessel containing $\mathrm{KOH}$ crystals, rises sharply, signifying the onset of the $\mathrm{KOH}$ dissolution in the distilled water, generated by the condenser. Eventually, as a consequence of the $\mathrm{KOH}$ dissolution in the water, the temperature of the $\mathrm{KOH}$ solution formed increased to $55.9^{\circ} \mathrm{C}$. It should also be pointed out that the maximal temperature achieved in the dissolution of $\mathrm{KOH}$ in the water under vacuum conditions, is lower compared to that attained at atmospheric pressure, i.e., $+55.9{ }^{\circ} \mathrm{C}$ under vacuum, versus $+73.6{ }^{\circ} \mathrm{C}$ at atmospheric pressure for the $70 \% \mathrm{KOH}$ solution concentration.

The overall reaction can be written as:

$$
\underbrace{\mathrm{NH}_{4} \mathrm{NO}_{3}}_{\text {solution }}+\text { heat } \rightarrow \underbrace{\mathrm{H}_{2} \mathrm{O}}_{\text {liquid }}+\underbrace{\mathrm{KOH}}_{\text {pure }}+\text { exothermal heat }
$$


In this reaction the overall exothermal heat released, was $236 \mathrm{~kJ} / \mathrm{kg}$.

In both experiments, the curve segments of the water evaporation shown in Fig. 2 and Fig. 3 display a nontrivial character and will be explained in our further research.
In the tested water distillation system, a separator plays a significant role because it prevents any penetration of the solute from the upper vessel to the lower vessel and its subsequent chemical reaction with the generation of $\mathrm{NH}_{3}$ gas adversely affecting the thermochemical reactions under study.

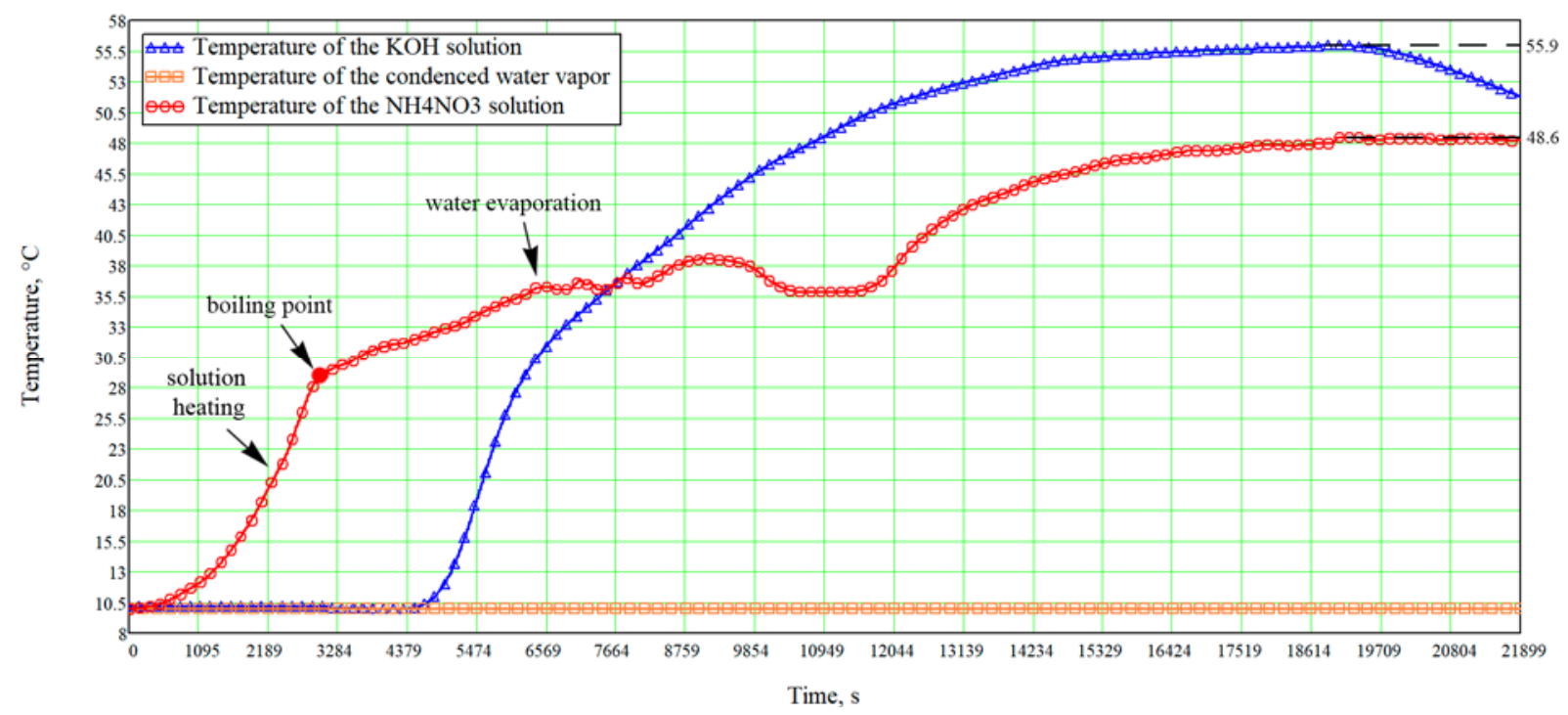

Fig. 3. Time evolution of the temperatures measured in the $\underbrace{\mathrm{NH}_{4} \mathrm{NO}_{3}}_{\text {solution }} \rightarrow \underbrace{\mathrm{H}_{2} \mathrm{O}}_{\text {liquid }} \rightarrow \underbrace{\mathrm{KOH}}_{\text {pure }}$ experiment

\section{Conclusions}

In this paper, an experimental testing of the water distillation system has been carried out with the aim of studying the ability to generate exothermal heat and endothermal cooling, with the natural mixing of the solvent and solute under vacuum conditions. On the basis of the results obtained, the following conclusions can be drawn.

- In the $\mathrm{KOH} \rightarrow \mathrm{H}_{2} \mathrm{O} \rightarrow \mathrm{NH}_{4} \mathrm{NO}_{3}$ experiment, the overall endothermal effect of the $\mathrm{NH}_{4} \mathrm{NO}_{3}$ dissolution reaction in the water, distilled from the $\mathrm{KOH}$ solution, is stronger than that observed at atmospheric pressure. Thus, during natural mixing, endothermal cooling generation occurs with the temperature dropping up to $-8.9{ }^{\circ} \mathrm{C}$ under vacuum conditions, with $-153 \mathrm{~kJ} / \mathrm{kg}$ of the heat being absorbed.

- In the $\mathrm{NH}_{4} \mathrm{NO}_{3} \rightarrow \mathrm{H}_{2} \mathrm{O} \rightarrow \mathrm{KOH}$ experiment, the overall exothermal effect of the $\mathrm{KOH}$ dissolution reaction in the water distilled from the $\mathrm{NH}_{4} \mathrm{NO}_{3}$ solution is weaker than that observed at atmospheric pressure. Thus, during natural mixing, the exothermal heat generation occurs with the temperature rising up to $+55.9^{\circ} \mathrm{C}$ under vacuum conditions, with $236 \mathrm{~kJ} / \mathrm{kg}$ of the heat being released.

- It is revealed that a separator is an essential element of the tested water distillation system because it eliminates the possibility of any penetration of the solute from the upper chemical vessel to the lower chemical vessel, with the subsequent generation of ammonia gas and degradation of the thermal effect in the dissolution reactions.

- It has also been found that the $\mathrm{NH}_{4} \mathrm{NO}_{3}$ solution has a much lower boiling point than the $\mathrm{KOH}$ solution, i.e., $28.7{ }^{\circ} \mathrm{C}$ for the $\mathrm{NH}_{4} \mathrm{NO}_{3}$ solution, versus $78.4^{\circ} \mathrm{C}$ for the $\mathrm{KOH}$ solution. This allows entire water evaporation from the $\mathrm{NH}_{4} \mathrm{NO}_{3}$ solution at much lower temperatures, compared to the $\mathrm{KOH}$ solution.

The experimental results obtained in this study will be used to develop a dual thermochemical heat storage and cooling generating system, enabling the utilization of solar heat in the summer. In the future, we also intend to study the kinetics of water evaporation from different liquid solutions, such as ammonium nitrate $\mathrm{NH}_{4} \mathrm{NO}_{3}$, potassium hydroxide $\mathrm{KOH}$ and sodium hydroxide $\mathrm{NaOH}$ under vacuum conditions.

\section{References}

1. L.F. Cabeza et al., Renew. Energ. 110, 3-39 (2016)

2. G. Li et al., Int. J. Refrig. 35, 2053-2077 (2012)

3. D. Aydin et al., Renew. Sust. Energ. Rev. 41, 356367 (2015)

4. A. Fopah Lele, A Thermochemical Heat Storage System for Households: Combined Investigations of Thermal Transfers Coupled to Chemical Reactions (Springer International Publishing, Switzerland, 2016)

5. S. Bespalko et al., E3S Web of Conferences 118, 01026 (2019) 